DOI: https://doi.org/10.24127/ajpm.v9i4.3212

\title{
PENGEMBANGAN LEMBAR KERJA PESERTA DIDIK BERWAWASAN AL-QUR'AN DAN BUDAYA MINANGKABAU DALAM PEMBELAJARAN MATEMATIKA KELAS X
}

\author{
Rozi Fitriza $^{1 *}$, Mezi Szah Putra ${ }^{2}$, Duski Samad ${ }^{3}$ \\ ${ }^{1,2,3}$ Universitas Islam Negeri Imam Bonjol, Padang, Indonesia \\ ${ }^{*}$ Corresponding author.Korong Gadang, 25156, Padang, Indonesia \\ E-mail: $\quad$ rozifitriza@uinib.ac.id ${ }^{1 *}$ \\ mezyszahputra96@gmail.com $^{2}$ \\ duskisamad@uinib.ac.id ${ }^{3)}$
}

Received 04 November 2020; Received in revised form 10 December 2020; Accepted 27 December 2020

\begin{abstract}
Abstrak
Pemerintah provinsi Sumatera Barat mencanangkan program integrasi pendidikan al-Quran dan budaya alam Minangkabau pada setiap mata pelajaran di tingkat SMA/SMK. Untuk itu diperlukan pedoman pengintegrasian yang bersifat implementatif. Penelitian ini bertujuan mengembangkan dan menghasilkan bahan ajar berupa Lembar Kerja Peserta Didik (LKPD) matematika berwawasan al-Qur'an dan budaya Minangkabau yang memenuhi kriteria valid dan praktis untuk peserta didik kelas X. Penelitian ini menggunakan metode penelitian dan pengembangan. Model pengembangan yang digunakan adalah model 4-D dengan tahapan Define, Design, Develop dan Disseminate. LKPD hasil pengembangan diujikan terhadap satu kelompok peserta didik dan pendidik kelas X SMAN 2 Padang Panjang. Instrumen penelitian yang digunakan berupa: pedoman wawancara dengan peserta didik dan pendidik (pada tahap define dan develop), lembar analisis konsep/tugas, lembar validasi, lembar observasi, dan angket respon peserta didik dan pendidik. Analisis data kualitatif dilakukan dengan langkah: reduksi/kodifikasi data, penyajian data dan penarikan kesimpulan. Data kuantitatif berupa tingkat validitas dan praktikalitas, disajikan dalam bentuk persentase dan kategori. Penelitian ini menghasilkan LKPD materi sistem persamaan linier tiga variabel berwawasan al-Qur'an dan budaya Minangkabau. Permasalahan dan soalsoal disajikan menggunakan konteks budayaMinangkabau. Ayat-ayat al-Qur'an pada setiap LKPD terkait dengan materi yang dibahas. Hasil validasi ahli menunjukkan bahwa LKPD yang dikembangkan sangat valid dengan persentase kevalidan 84,27\%. Respon peserta didik menunjukkan produk LKPD ini sangat praktis dengan persentase $89,03 \%$. Sedangkan pendidik menilai LKPD ini praktis dengan persentase $80,2 \%$. Jadi LKPD materi sistem persamaan linier tiga variabel berwawasan al-Qur'an dan budaya Minangkabau dapat digunakan dalam pembelajaran matematika kelas X.
\end{abstract}

Kata kunci: Al-Qur'an; budaya Minangkabau; LKPD; matematika; R\&D

\begin{abstract}
The West Sumatra government implements the integration of Al-Quran education and Minangkabau natural culture in every subject at the SMA / SMK level. For this reason, an implementative integration guideline is needed.This study aims to develop and to create math teaching student worksheets that make use of concepts that come from the Al-Qur'an and Minangkabau culture. The worksheets fulfill valid and practical criteria for grade $X$ students. This study applies research and development methods. The development model used is a 4-D model which consists of the Define, Design, Develop, and Disseminate stages. The developed LKPD was tested on a group of class X students and educators at SMAN 2 Padang Panjang. The research instruments used were: interview guides with students and educators (at the define and develop stage), concept/task analysis sheets, validation sheets, observation sheets, and student and educator response questionnaires. Qualitative data were analyzed by reducing/codifying data, presenting data, and drawing conclusions. Quantitative data in the form of validity and practicality made percentages and categorization. This research produces LKPD with the insight of the Al-Qur'an and Minangkabau culture for the material of the system of linear equations three variables. The problems and questions presented are using the Minangkabau cultural context. The verses of the Al-Qur'an that are presented are related to the material being discussed. The results of expert validation show that the
\end{abstract}


DOI: https://doi.org/10.24127/ajpm.v9i4.3212

developed LKPD is very valid with a validity percentage of $84.27 \%$. The response of students showed that the product produced was very practical with a percentage of $89.03 \%$, while the educators considered that this LKPD was practical with a percentage of $80.2 \%$. So LKPD with the insight of the Al-Qur'an and Minangkabau culture is valid and practically used in class X mathematics learning in the material of the system of linear equations three variables.

Keywords: Al-Qur'an; Minangkabau culture; R\&D; student worksheet

\section{PENDAHULUAN}

Generasi emas Indonesia memiliki tiga dimensi, yaitu: kemampuan intelektual yang hebat, ketaatan beragama, dan kekuatan budaya lokal. Pendidikan yang berkualitas akan membantu terwujudnya generasi emas. Proses pembelajaran setiap mata pelajaran harus mampu mewujudkan tiga dimensi ini. Begitu pula proses pembelajaran matematika, peserta didik diharapkan mampu menguasai materi matematika dengan baik, taat beragama, dan menghargai budaya bangsa.

Arah pendidikan menuju generasi emas Indonesia tahun 2045 disikapi oleh dinas pendidikan provinsi Sumatera Barat dengan menyusun pedoman integrasi al-Quran dan budaya alam Minangkabau pada setiap mata pelajaran di SMA/SMK. Pedoman ini dibuat sebagai tindak lanjut peraturan gubernur Sumatera Barat nomor 73 tahun 2012 tentang petunjuk pelaksanaan pendidikan karakter di sekolah. Pedoman pengintegrasian berisi contoh silabus, RPP dan suplemen bahan ajar materi pilihan yang memuat ayat-ayat al-Qur'an dan falsafah-falsafah Minangkabau (Sarmalena \& Susanti, 2017). Adanya peraturan dan pedoman ini menuntut pendidik dapat menyelenggarakan pembelajaran yang terintegrasi alQur'an dan budaya Minangkabau.

Pembelajaran matematika dengan memasukkan nilai-nilai agama/
al-Qur'an sangat mungkin dilakukan. Karena struktur al-Qur'an adalah sebuah struktur yang bersifat matematis (Al-Faqih, 2017). Matematikawan muslim dahulu menjadikan al-Qur'an sebagai rujukan dalam mengembangkan keilmuwan matematika di berbagai kajian, seperti: teori bilangan, aritmatika, aljabar dan geometri. Beberapa ayat dalam al-Qur'an yang berkaitan dengan matematika, digunakan para ilmuwan muslim untuk mengembangkan matematika (Hussain \& Ramli, 2017). Matematika merupakan ilmu yang menggabungkan kesatuan dan karakter pemikiran Islam dan mengkaji kebutuhan religi umat (Nu'man, 2016).

Pembelajaran matematika berbasis al-Quran telah terbukti efektif dalam menanamkan nilai-nilai agama peserta didik. Menurut Sugilar, et.al (2019), mengaitkan al-Qur'an dalam pembelajaran matematika menjadikan peserta didik mampu meyakini kebesaran Allah SWT. Setiawan \& Thahir (2016) juga membuktikan bahwa peserta didik yang pembelajaran matematikanya diintegrasikan dengan keIslaman memiliki tingkat religiusitas lebih tinggi dari pada peserta didik yang pembelajaran matematikanya dengan cara biasa.

$$
\text { Penggunaan budaya lokal }
$$
sebagai konteks atau sarana belajar matematika juga sudah banyak diteliti. Fitriza dan Gunawan (2018) menggunakaan benda budaya tabuik 
dalam pembelajaran bangun ruang sisi datar. Pembelajaran matematika yang menggunakan pendekatan yang berbasis budaya terbukti memberikan pencapaian belajar yang lebih dibanding dengan pembelajaran konvensional (Abiam et al., 2016). Penggunaan model project based learning yang bermuatan budaya dapat meningkatkan kemampuan koneksi matematis peserta didik (Rizka \& Mastur, 2014).

$$
\text { Hasil wawancara dengan }
$$
pendidik matematika di SMA 2 Padang Panjang terungkap bahwa pendidik masih kesulitan menginteggrasikan pembelajaran matematika dengan alQuran dan budaya Minangkabau. Pada pedoman pengintegrasian, hanya terdapat ayat-ayat al-Qur'an dan falsafah Minangkabau yang digunakan pada bagian kegiatan pendahuluan pembelajaran, sebagai motivasi untuk peserta didik. Pendidik berharap ayat alQur'an dan aspek budaya Minangkabau (selain falsafah) hendaknya terkait dengan materi matematika yang diajarkan.

Beberapa penelitian juga mengungkapkan bahwa masih terbatasnya kemampuan pendidik dalam membuat perencanaan, melaksanakan pembelajaran yang terintegrasi (Junaidi et al., 2020; Setiawan \& Thahir, 2016). Untuk itu diperlukan perangkat pembelajaran yang dapat membantu pendidik mengaitkan matematika dan al-Qur'an serta menggunakan konteks budaya yang dekat dengan kehidupan peserta didik. Bahan ajar terintegrasi nilai budaya dan keIslaman memungkinkan untuk dirancang dan sangat bermanfaat (Idris, 2019).

\begin{tabular}{lcr}
\multicolumn{1}{c}{ Selama ini, sudah } & terdapat \\
beberapa penelitian & tentang \\
pembelajaran matematika yang & mand \\
terintegrasi al-Quran/nilai Islam dan \\
pembelajaran matematika yang
\end{tabular}

menggunakan konteks budaya. Penelitian tentang pembelajaran matematika yang dikaitkan dengan kedua aspek, al-Qur'an dan budaya masih sebatas membahas tentang: model-model integrasi (Mutijah, 2018), prinsip, teori dan metode integrasi (Sugilar et al., 2019), perspektif dosen dan mahasiswa tentang integrasi (Idris, 2019). Untuk itu, bahasan dalam penelitian ini tidak hanya sebatas tataran teori tetapi dalam tataran membantu pendidik mengimplementasi pembelajaran matematika yang dikaitkan dengan al-Quran dan budaya lokal.

Berdasarkan uraian di atas maka penelitian ini bertujuan untuk mengembangkan dan menghasilkan bahan ajar berupa Lembar Kerja Peserta Didik (LKPD). LKPD berfungsi menunjang pelaksanaan pembelajaran sekaligus mempermudah peserta didik memahami materi, karena LKPD merupakan bahan ajar yang ringkas dan kaya akan tugas untuk berlatih (Prastowo, 2014) LKPD yang dikembangkan untuk kelas $X$, di dalamnya terdapat wawasan tentang alQur'an dan wawasan tentang budaya Minangkabau. Konteks budaya Minangkabau dan ayat-ayat al-Qur'an yang digunakan relevan dengan materi.

\section{METODE PENELITIAN}

Untuk itu digunakan metode penelitian dan pengembangan. Model pengembangan yang digunakan adalah model 4-D (define, design, develop, and disseminate) (Thiagarajan et al., 1974)

Penelitian ini menggunakan tiga dari empat tahapan model 4-D. Tahapan define, terdiri atas 5 langkah; pertama, analisis awal-akhir, berkaitan dengan mengetahui permasalahan dasar dalam pengembangan bahan ajar/LKPD. Kedua, analisis peserta didik, berkaitan 
dengan analisis karakteristik peserta didik yang meliputi kemampuan awal, pengalaman, sikap terhadap pembelajaran. Ketiga, analisis tugas, berkaitan rumusan kompetensi yang harus dicapai peserta didik. Keempat, analisis konsep berkaitan dengan mengidentifikasi konsep-konsep penting yang diajarkan dan menyusunnya secara sistematis. Kelima, penentuan tujuan pembelajaran, menyusun sejumlah tujuan pembelajaran untuk diselaraskan dengan konsep dan tugas yang dirancang.

Tahapan design, bertujuan untk merancang prototipe LKPD. Terdiri atas empat langkah, yang pertama, merancang tes yang berkaitan dengan tujuan yang telah ditetapkan. Kedua, menyiapkan media berkaitan dengan bahan ajar/LKPD yang telah dirancang. Ketiga, memilih rancangan format LKPD. Keempat, desain awal, menyiapkan seluruh kegiatan pembelajaran dan LKPD.

Tahapan develop, merupakan tahapan memodifikasi prototipe awal. Terdiri atas dua langkah, pertama penilaian dari ahli, untuk memperoleh saran/masukan atas LKPD yang dirancang. Para ahli diminta menilai LKPD untuk perbaikan LKPD agar valid, berkualitas, dan dapat digunakan. Langkah kedua, tes pengembangan, dimana LKPD dicobakan ke peserta didik. Respon, reaksi dan komentar dari peserta didik dijadikan bahan perbaikan LKPD.

Subjek penelitian ini adalah peserta didik kelas $\mathrm{X}$ dan pendidik di SMAN 2 Padang Panjang. Peserta didik untuk uji coba LKPD berasal dari satu kelas. Pendidik yang menjadi subjek adalah dua orang pendidik yang mengajar matematika wajib pada kelas $\mathrm{X}$.
Tabel 1 memperlihatkan instrumen yang digunakan pada setiap tahapan pengembangan

:Tabel 1. Instrumen penelitian.

Tahapan Instrumen

\begin{tabular}{cc}
\hline Define & - Pedoman Wawancara \\
& dengan pendidik. \\
& - Pedoman Wawancara \\
& dengan peserta didik \\
& - Lembar analisis \\
& konsep/kurikulum, \\
& tujuan pembelajaran \\
& dan tugas \\
Develop & - Lembar validasi ahli \\
& - Lembar observasi \\
& penggunaan LKPD \\
& - Angket respon \\
& pendidik \\
& - Angket respon peserta \\
& didik $\quad$ \\
- Pedoman wawancara & dengan peserta didik \\
& dan pendidik \\
\hline
\end{tabular}

Aspek validitas yang dinilai meliputi: aspek kelayakan isi, kelayakan penyajian, kebahasaan dan kegrafisan. Aspek praktikalitas meliputi: aspek daya tarik, efisiensi waktu, kemudahan penggunaan dan manfaat. Aspek pratikalitas menjadi dasar untuk pembuatan angket, lembar observasi dan pedoman wawancara.

Berdasarkan instrumen penelitian yang digunakan, maka data dikategorikan kepada data yang bersifat kualitatif (wawancara, analisis konsep/kurikulum, observasi) dan data kuantitatif (validitas, angket respon). Data kualitatif dianalisis dengan langkah: reduksi data (melakukan koding dan klasifikasi), selanjutnya menyajikan data secara sistematis dan diakhiri menarik kesimpulan. Sedangkan data kuantitatif dianalisis 
DOI: https://doi.org/10.24127/ajpm.v9i4.3212

dengan menggunakan persentase dan kriteria seperti pada Tabel 2.

Tabel 2. Kriteria validitas/praktikalitas LKPD

\begin{tabular}{cl}
\hline \multicolumn{1}{c}{$\begin{array}{c}\text { Nilai } \\
(\boldsymbol{\%})\end{array}$} & \multicolumn{1}{c}{ Kategori } \\
\hline $81-100$ & Sangat valid/praktis \\
$61-80$ & Valid/praktis \\
$41-60$ & Cukup valid/praktis \\
$21-40$ & Kurang valid/praktis \\
$0-20$ & Tidak valid/praktis \\
\hline
\end{tabular}

Dimodifikasi dari Riduwan (2012)

\section{HASIL DAN PEMBAHASAN}

Berikut ini diuraikan hasil tiap tahapan pengembangan Lembar Kerja Peserta Didik (LKPD) matematika berwawasan al-Qur'an dan budaya Minangkabau.

\section{Tahap define}

Tahap ini dimulai dengan analisis awal-akhir yang mengkaji masalah yang dialami pendidik dalam mengembangkan bahan ajar yang berwawasan budaya lokal dan alQur'an. Pendidik mengalami kendala dalam mencari konteks budaya dan alQur'an yang terkait dengan materi matematika yang sedang diajarkan. Contoh yang diberikan pada dokumen pedoman integrasi pembelajaran matematika dengan al-Qur'an dan budaya alam Minangkabau, untuk aspek budaya hanya terbatas pada falsafah atau pepatah-petitih orang Minangkabau. Ayat-ayat al-Quran perlu dilengkapi dengan tafsir nya sehingga memudahkan pendidik mengaitkan dengan materi matematika yang sedang dibahas. Selanjutnya dari wawancara dengan pendidik diperoleh data tentang kemampuan peserta didik secara akademik cukup baik. Peserta didik juga sudah dibiasakan bekerja secara kolaboratif dalam kelompok. Pendidik dan peserta didik mengemukakan hal yang sama bahwa konteks-konteks budaya lokal belum banyak digunakan dalam pembelajaran matematika atau digunakan dalam bahan ajar.

Analisis terhadap konsep, didapatkan materi matematika wajib yang dipelajari siswa kelas $\mathrm{X}$ meliputi: a) Persamaan nilai mutlak, b) Sistem persamaan linier tiga variabel, c) Fungsi. Mengingat keterbatasan waktu dan kemampuan, maka dipilih materi sistem persamaan linear tiga variabel (SPLTV) menjadi konsep yang dikaji dalam LKPD yang dikembangkan. Konsep disusun sedemikian rupa sehingga sesuai dengan kompetensi (menyusun dan menyelesaikan permasalahan kontekstual yang berkaitan dengan SPLTV) dan tujuan yang telah ditentukan terkait dengan pembelajaran matematika bermuatan budaya dan al-Qur'an.

\section{Tahap design}

Tahap ini merupakan kelanjutan dari tahap define, dimulai dengan mengurutkan materi, selanjutnya menentukan format LKPD, yang terdiri dari: pendahuluan, isi dan, penutup. Kemudian dilanjutkan dengan penulisan LKPD yang mengacu kepada standar isi pada kurikulum 2013 dan format yang telah ditetapkan. Penulisan LKPD menggunakan beberapa aplikasi komputer yaitu Microsoft office word dan coreldraw X8.

Pada bagian pendahuluan LKPD terdapat halaman cover, halaman depan, kata pengantar, daftar isi, panduan penggunaan LKPD, halaman berisi kompetensi dasar, indikator, dan tujuan pembelajaran serta diagram alir materi. Cover berisi judul LKPD, gambar masjid raya Sumatera Barat yang mencerminkan nilai agama dan budaya serta gambar songket asli Minangkabau. Terdapat kolom identitas peserta didik 
serta nama penulis LKPD. Pada cover belakang terdapat gambar songket serta kalimat motivasi dari film Surau dan Silek, yaitu "Tiga hal yang penting untuk anak Minangkabau: shalat, shalawat, silek".

Pada bagian isi LKPD terdiri atas: judul tiap LKPD, ayat al-Qur'an yang berkaitan dengan materi yang sedang dipelajari pada bagian "Ayo Telusuri", penggunaan konteks budaya digunakan dalam mempelajari konsep serta pada soal-soal latihan. Konteks masalah yang disajikan bukan hal yang dibuat-buat melainkan sesuatu fakta yang ada dalam kehidupan (Sugilar et al., 2019).

Bagian penutup terdiri daftar pustaka dan glosarium. Daftar pustaka berisi referensi yang digunakan dalam penulisan LKPD yang terdiri dari buku/dokumen yang terkait dengan materi matematika, al-Qur'an, terjemahan dan tafsir. Glosarium berisi istilah-istilah yang sukar atau tidak diketahui secara umum. Selanjutnya dirancang tes terkait materi SPLTV, untuk mengukur kemampuan peserta didik setelah belajar menggunakan LKPD berwawasan al-Qur'an dan budaya Minangkabau. Dipersiapkan media seperti LCD proyektor untuk penjelasan materi dan LKPD.

\section{Tahap develop}

Hasil rancangan awal LKPD pada tahap design disebut dengan prototipe 1 . Pada tahap develop, prototipe 1 dinilai validitasnya oleh 6 (enam) orang ahli, yang terdiri atas: ahli matematika, ahli pembelajaran matematika, ahli bahasa, ahli budaya dan ahli tafsir. Aspek yang dinilai meliputi aspek kelayakan isi, penyajian, kebahasaan dan kegrafisan. Tabel 3 menunjukkkan hasil penilaian validitas dari para ahli:
Tabel 3. Hasil penilaian ahli

\begin{tabular}{|c|c|c|c|}
\hline No. & $\begin{array}{c}\text { Aspek yang } \\
\text { dinilai }\end{array}$ & $\begin{array}{c}\text { Nilai } \\
(\%)\end{array}$ & Kriteria \\
\hline 1 & $\begin{array}{l}\text { Aspek } \\
\text { kelayakan } \\
\text { isi }\end{array}$ & 84,6 & $\begin{array}{c}\text { Sangat } \\
\text { Valid }\end{array}$ \\
\hline 2 & $\begin{array}{l}\text { Aspek } \\
\text { penyajian }\end{array}$ & 81,25 & $\begin{array}{l}\text { Sangat } \\
\text { valid }\end{array}$ \\
\hline 3 & $\begin{array}{l}\text { Aspek } \\
\text { kebahasaan }\end{array}$ & 83,75 & $\begin{array}{l}\text { Sangat } \\
\text { valid }\end{array}$ \\
\hline 4 & $\begin{array}{l}\text { Aspek } \\
\text { kegrafisan }\end{array}$ & 87,5 & $\begin{array}{c}\text { Sangat } \\
\text { valid }\end{array}$ \\
\hline \multicolumn{2}{|c|}{ Rata-rata nilai } & 84,27 & $\begin{array}{c}\text { Sangat } \\
\text { valid }\end{array}$ \\
\hline
\end{tabular}

Semua ahli merekomendasikan bahwa prototipe 1 LKPD ini dapat digunakan dengan sedikit revisi. Selain memberikan penilaian secara kuantitatif, ahli juga memberikan tanggapan dan saran untuk perbaikan prototipe 1. Tanggapan dan saran dari ahli dirangkum dalam Tabel 4.

Berdasarkan penilaian, tanggapan dan saran dari ahli, dilakukan modifikasi terhadap prototipe 1 . Hasil modifikasi ini disebut dengan prototipe 2, selanjutnya diujicobakan kepada peserta didik dan pendidik untuk dilihat kepraktisan penggunaannya.

LKPD diujicobakan di kelas $\mathrm{X}$ SMAN 2 Padang Panjang. Pada saat peserta didik mengerjakan LKPD dilakukan observasi yang dilengkapi dengan wawancara untuk melihat respon peserta didik terhadap prototipe 2 LKPD. Hasil observasi dan wawancara menunjukkan bahwa: peserta didik belum terbiasa menyelesaikan persoalan dengan langkah-langkah sitematis seperti yang terdapat di LKPD, sehinggga mereka mengatakan bahwa soalsoal/permasalahan yang diberikan agak sukar. Tetapi dengan kegiatan yang ada di LKPD peserta didik terlihat aktif dalam pembelajaran. 
DOI: https://doi.org/10.24127/ajpm.v9i4.3212

Tabel 4. Tanggapan dan saran para ahli

\begin{tabular}{|c|c|c|}
\hline No. & $\begin{array}{c}\text { Aspek } \\
\text { yang } \\
\text { dinilai }\end{array}$ & $\begin{array}{l}\text { Tanggapan dan } \\
\text { saran }\end{array}$ \\
\hline 1 & $\begin{array}{l}\text { Aspek } \\
\text { kelayakan } \\
\text { isi }\end{array}$ & $\begin{array}{l}\text { Beberapa masalah } \\
\text { kontekstual yang } \\
\text { disajikan di LKPD, } \\
\text { belum sepenuhnya } \\
\text { terkait dengan } \\
\text { budaya } \\
\text { Minangkabau. } \\
\text { Berikan penjelasan } \\
\text { terhadap tafsir } \\
\text { ayat-ayat al-Qur'an } \\
\text { yang disajikan }\end{array}$ \\
\hline 2 & $\begin{array}{l}\text { Aspek } \\
\text { penyajian }\end{array}$ & $\begin{array}{l}\text { Kegiatan di LKPD } \\
\text { belum sepenuhnya } \\
\text { menuntun peserta } \\
\text { didik menemukan } \\
\text { konsep. Konteks } \\
\text { pada soal-soal } \\
\text { yang disajikan } \\
\text { belum bervariasi. }\end{array}$ \\
\hline 3 & $\begin{array}{l}\text { Aspek } \\
\text { kebahasaan }\end{array}$ & $\begin{array}{l}\text { Perbaiki ejaan, } \\
\text { tanda baca. } \\
\text { Gunakan kata dan } \\
\text { kalimat yang } \\
\text { efektif, sehingga } \\
\text { mudah dipahami } \\
\text { peserta didik }\end{array}$ \\
\hline 4 & $\begin{array}{l}\text { Aspek } \\
\text { kegrafisan }\end{array}$ & $\begin{array}{lr}\text { Cover } & \text { depan } \\
\text { terlihat } & \text { padat, } \\
\text { menumpuk. } & \text { Pilih } \\
\text { warna } & \text { yang } \\
\text { menarik, } & \text { sesuai } \\
\text { dengan } & \text { peserta } \\
\text { didik } & \end{array}$ \\
\hline
\end{tabular}

Peserta didik mengatakan bahwa bahasa dan petunjuk penggunaan LKPD sudah jelas, materi yang disajikan mudah dipahami, sehingga membantu mereka dalam menemukan konsep. Selain itu desain atau format LKPD menarik, LKPD juga telah memberikan wawasan tentang al-Qur'an dan budaya Minangkabau yang dikaitkan dengan materi sistem persamaan linear tiga variabel. Hal ini sejalan dengan temuan Muslimahayati (2020), bahwa soal/tugas yang dikaitkan dengan budaya lokal akan menarik serta memberikan tambahan pengetahuan.

Angket tanggapan peserta didik terhadap prototipe 2 LKPD, menunjukkan bahwa LKPD yang dirancang sangat praktis (dengan nilai $89,03 \%$ ). Rekomendasi yang diberikan peserta didik bahwa LKPD dapat digunakan dengan revisi kecil dan sebagian kecil peserta didik mengatakan bahwa LKPD ini dapat digunakan tanpa revisi. Sedangkan tanggapan pendidik kelas $\mathrm{X}$ tentang praktikalitas LKPD matematika berwawasan al-Qur'an dan budaya Minangkabau didapatkan bahwa LKPD praktis digunakan (nilai rata-rata $80,2 \%)$.

Persentase nilai praktikalitas masing-masing aspek (daya tarik, efisiensi waktu, kemudahan penggunaan dan manfaat) ditunjukkan pada grafik penilaian praktikalitas LKPD pada Gambar 1.

Terlihat bahwa penilaian terendah diberikan pada aspek efisiensi waktu. Hal ini sejalan dengan hasil wawancara dengan pendidik, bahwa pembelajaran dengan LKPD matematika berwawasan al-Qur'an dan budaya Minangkabau dapat terlaksana, tetapi waktu kurang mencukupi membahas semua kegiatan/komponen yang terdapat pada masing-masing LKPD.

Pendidik juga mengungkapkan bahwa LKPD yang dirancang menarik bagi peserta didik, membuat peserta didik aktif dalam pembelajaran. Selain itu prototipe 2 ini sudah menggunakan bahasa dan petunjuk yang jelas, sesuai dengan tingkat pemahaman peserta didik. Dari aspek isi, LKPD ini lengkap, 
disertai juga dengan kegiatan yang mempermudah peserta didik memahami konsep. Jadi menurut pendidik LKPD berwawasan al-Qur'an dan budaya
Minangkabau ini praktis digunakan dalam pembelajaran sistem persamaan linear tiga variabel.

\section{Penilaian Praktikalitas LKPD}

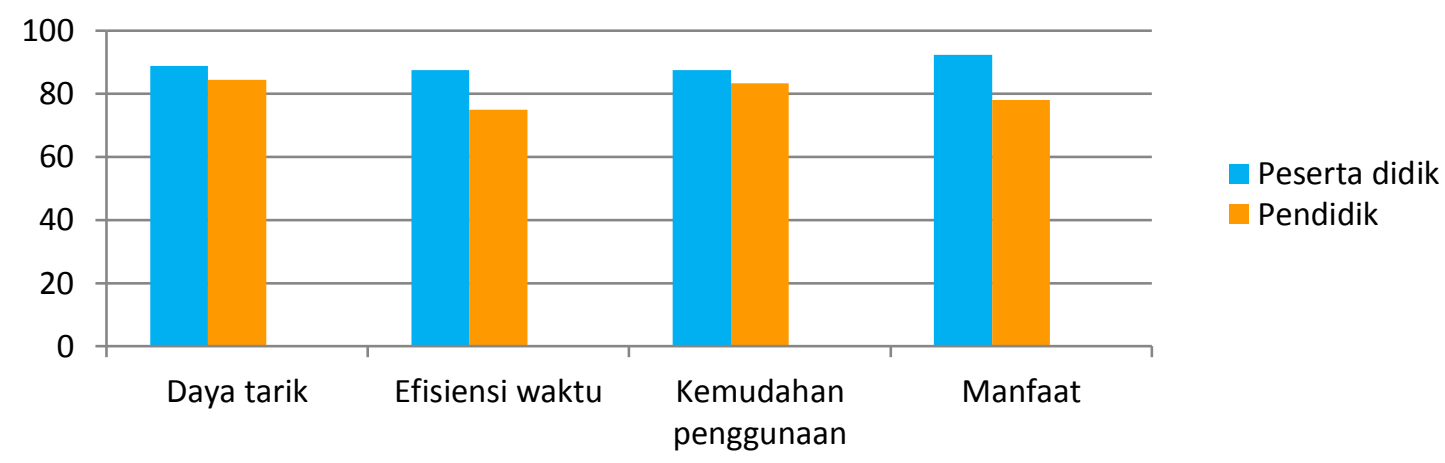

Gambar 1. Grafik persentase penilaian praktikalitas LKPD.

Hasil penelitian ini sejalan dengan hasil penelitian Hamdi \& Ermawati (2018) bahwa perangkat pembelajaran yang valid, praktis dan efektif serta menggunakan masalahmasalah yang berkaitan dengan Islam dapat meningkatkan motivasi dan hasil belajar peserta didik. Peserta didik dan pendidik sangat tertarik dengan konteks-konteks budaya yang disajikan. Pembelajaran berbasis budaya membuat belajar bermakna, membangun pengetahuan, keterampilan dan sikap (Rosa \& Orey, 2011). Wawasan budaya yang disajikan menambah pengetahuan dan minimbulkan sikap bangga terhadap budaya Minangkabau. Menghubungkan budaya dengan matematika tidak hanya membuat peserta memaknai konsep, tetapi juga menimbulkan sikap menghargai budaya sendiri dan budaya orang lain (D'Entremont, 2015)

Hasil uji coba berupa tanggapan dan respon peserta didik dan pendidik terhadap prototipe 2 LKPD menjadi dasar untuk menyempurnakan produk. Berikut ini produk akhir LKPD matematika berwawasan al-Qur'an dan budaya Minangkabau materi sistem persamaan linear tiga variabel untuk kelas X SMA:

Gambar 2 merupakan cover depan dan cover belakang LKPD. Pada cover depan terdapat gambar masjid raya Sumatera Barat yang merupakan artefak perpaduan unsur agama dan budaya. Selanjutnya terdapat kain songket khas Minangkabau. Pada sisi samping kiri terdapat 3 garis yang berwarna hitam, merah dan kuning, menyerupai warna marawa (bendera identitas Minangkabau). Cover depan juga dilengkapi dengan judul LKPD, kelas dan semester. Sedangkan cover belakang memiliki warna yang sama dengan cover depan, disertai gambar songket. Pada bagian bawah terdapat kata-kata motivasi/pituah untuk generasi muda Minangkabau.

Setelah cover terdapat halaman identitas LKPD (penulis, ukuran, desain), kemudian kata pengantar, panduan penggunaan LKPD (disertai dengan penjelasan tentang masingmasing komponen), dan daftar isi. Halaman satu dan dua berisi kompetensi dasar dan tujuan pembelajaran tiap pertemuan, serta diagram alir materi. Halaman tiga sampai dengan halaman 
32 merupakan halaman yang berisi LKPD kesatu sampai LKPD ketiga. Halaman 33 berisi glosarium dan halaman 34 merupakan daftar pustaka.
Jadi terdapat 34 (tiga puluh empat) halamam isi LKPD.


Gambar 2. Cover depan dan cover belakang.

Pada setiap LKPD diberikan petunjuk belajar, kemudian dilanjutkan dengan penyajian masalah-masalah yang menggunakan konteks budaya disertai langkah penyelesaian yang mengarahkan siswa menemukan konsep. Setelah itu ada komponen "Ayo Telusuri" berisi ayat-ayat al-Qur'an dan tafsirnya yang berkaitan dengan materi yang dibahas. Pada setiap LKPD juga terdapat komponen "Catatan" yang berisi kesimpulan tentang konsep yang telah dipelajari. Selain itu LKPD juga dilengkapi dengan latihan-latihan soal pada komponen "Ayo Berlatih".

LKPD 1 membahas tentang menyusun dan menemukan konsep sistem persamaan linier tiga variabel (SPLTV). Pada halaman 3 terdapat masalah ke-1 yang menggunakan konteks budaya, jenis-jenis motif batik khas Minangkabau (tanah liek, pucuak rabuang, rangkiang). Pada halaman 4 terdapat surat Al-Waqiah ayat 7-10 yang berkisah tentang 3 golongan manusia pada hari kiamat, yaitu golongan kanan/orang yang beriman, golongan kiri/orang yang ingkar serta golongan orang dahulu beriman pada dakwah Rasulullah. Ayat-ayat ini berkaitan dengan menyusun persamaan linier tiga variabel. Masalah ke-2 menggunakan konteks kerajinan (ukiran dan songket) dari daerah Pandai Sikek. Pada soal latihan menggunakan konteks budaya kerajinan anyaman dan bordir. Gambar 3 memperlihatkan konteks budaya dan wawasan al-Qur'an yang terdapat pada LKPD 1.

LKPD 2 membahas tentang penyelesaian SPLTV dengan metode subsitusi dan eliminasi. Bahasan LKPD 2 diawali dengan paparan surat al-Hajj ayat 52 dan kaitannya dengan istilah subsitusi dan eliminasi. Selanjutnya masalah ke-1 tentang lukisan objek wisata di Bukittinggi. Masalah ke-2 tentang jenis motif sulaman khas Minangkabau. Wawasan al-Qur'an dan budaya berkaitan dengan metode subsitusi dan eliminasi pada penyelesaian SPLTV terdapat pada Gambar 4. 
DOI: https://doi.org/10.24127/ajpm.v9i4.3212
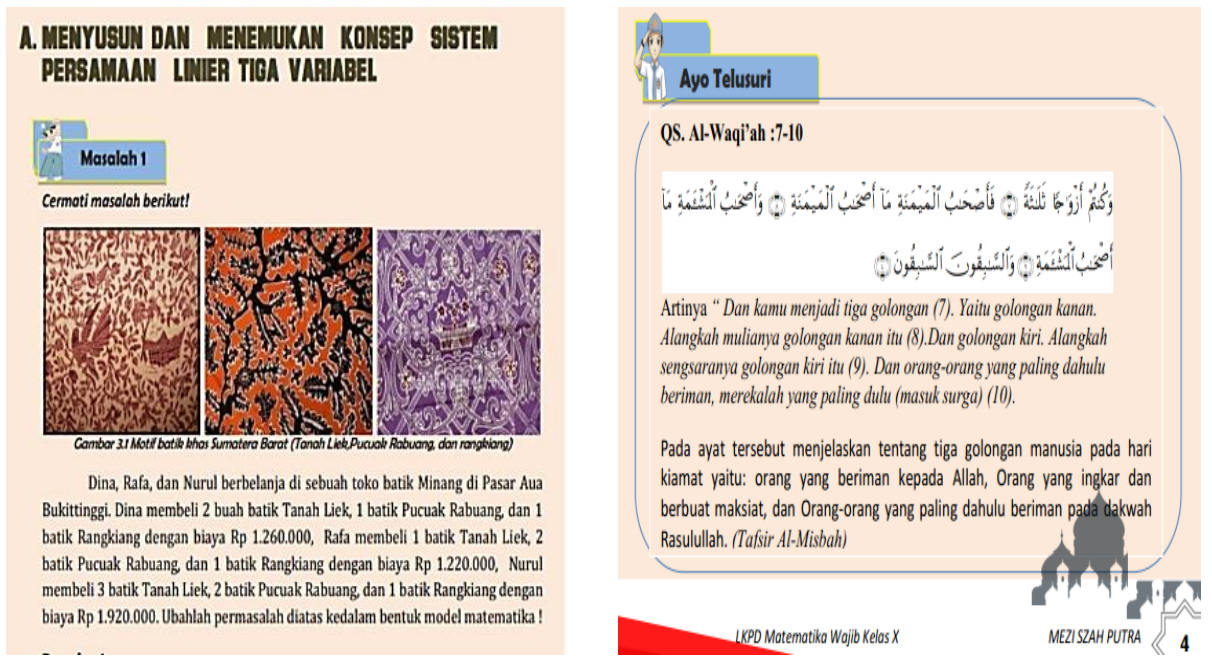

Gambar 3. Penggunaan wawasan al-Qur'an dan budaya Minangkabau pada LKPD 1.

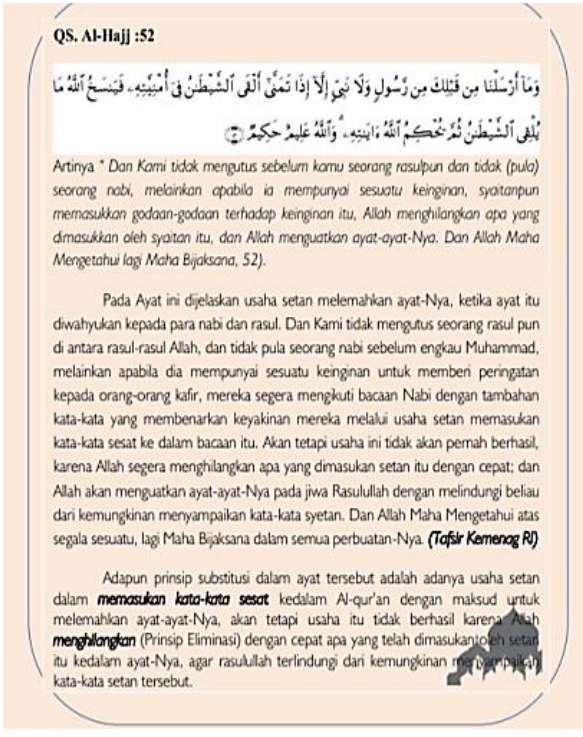

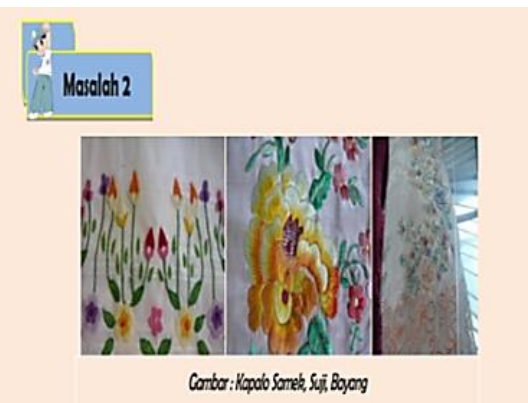

Leri, sur, dan Santi peregi ke pasar Ateh Bubittingow untuk membeli selendang dengan berbagaj jenis motif khas Vinangkhau. Leni mermbeli 2 selendang dengan motif Sulam Kapalo Samek, 2 selendang dengan motif Sulam Süji, 1 selendang dengan motif Sulam Bayang seharga Rp 1.500:000. Isur membeli 2 selendang dengan motif Sulam Kapalo Samek, 4 selendang dengan motif Sulam Süj seharga Rp 2370.000. Sedangkan Santi membeli 3 selendang dengan motif Sulam Bajang seharga Rp 1200.000. Tentukanlah harga masing. masing dari selendang tesechut?

Gambar 4. Penggunaan wawasan al-Qur'an dan budaya Minangkabau berkaitan dengan metode subsitusi dan eliminasi.

Penggunaan aktivitas tradisional pacu jawi (lomba berlari antar sapi/kerbau), digunakan pada masalah SPLTV di LKPD 2. Pada soal latihan digunakan konteks pengenalan jenisjenis ukiran khas Minangkabau (seperti: itiak pulang patang, pucuak rabuang, kaluak paku, siriah gadang).

Selain metode subsitusi dan eliminasi, dalam penyelesaian per- masalahan SPLTV dapat digunakan juga metode invers matriks. Pengenalan konsep penulisan matriks melalui surat al-An'am ayat 160, terdapat pada Gambar 5. Unsur budaya berupa aktivitas masa lampau digunakan pada LKPD 3, seperti Gambar 6.

Kejadian kedatangan Belanda ke Indonesia di bawah pimpinan Cornelis de Houtman, terjadinya perjanjian 
Musang (perjanjian antara Belanda dan kaum Padri/kelompok agama di Minangkabau) dan kejadian lahirnya tokoh wanita Minangkabau bernama Rohana Kudus, dijadikan konteks masalah SPLTV. Pada soal latihan peserta didik dikenalkan juga dengan kerajinan perak khas Koto Gadang, Kabupaten Agam Sumatera Barat.

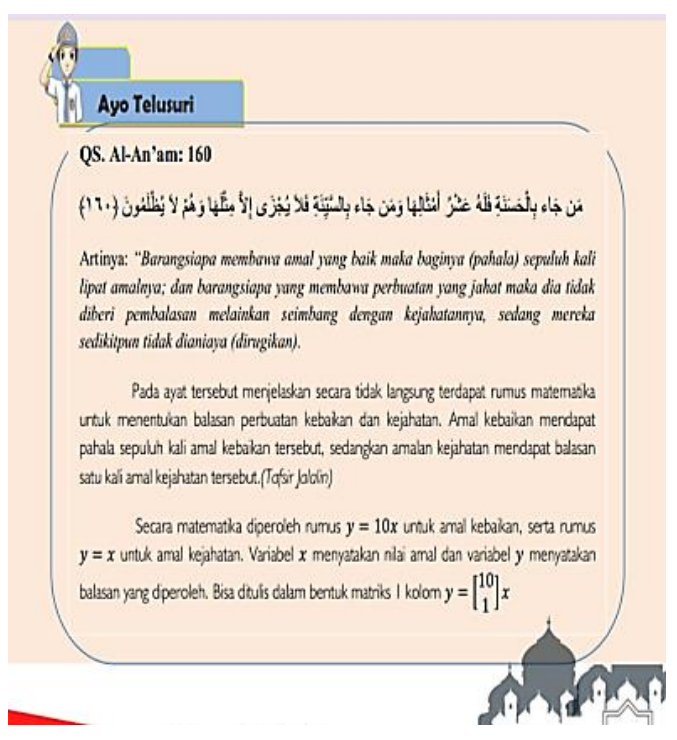

Gambar 5. Al-Qur'an dan penulisan matriks.

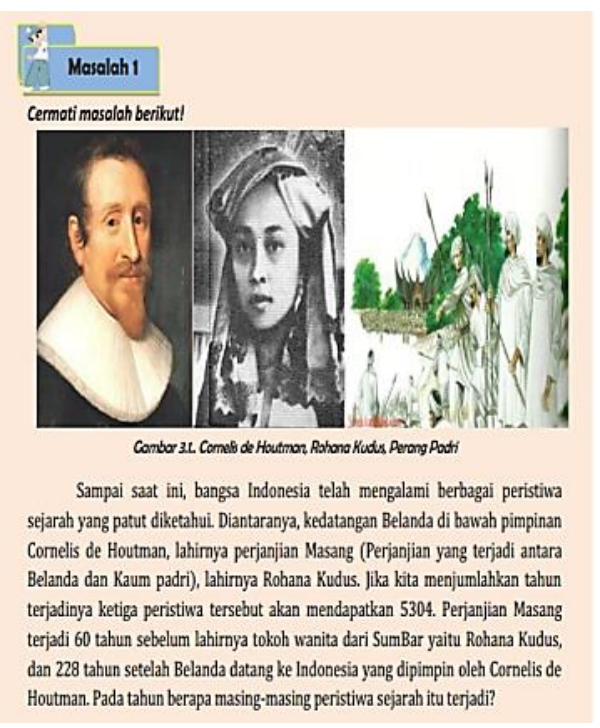

Gambar 6. Konteks budaya sejarah

Pada penelitian ini keterbatasan dari LKPD yang dihasilkan adalah konteks budaya yang digunakan kebanyakan berkaitan dengan jual beli produk budaya. Hal ini terkait dengan konsep SPLTV yang disampaikan. Konteks budaya dapat digunakan dalam menyampaikan sebuah konsep matematika, yang sekaligus memberikan penguatan karakter peserta didik (Ricardo, 2020).

Penanaman nilai-nilai keIslaman dalam pembelajaran matematika dapat dilakukan melalui metode pembelajaran, materi pelajaran atau proses pembelajaran (Istiqlal \& Jumadi, 2017). Pada penelitian ini wawasan tentang alQur'an disajikan pada aspek materi pelajaran. Pembelajaran yang didesain dengan ciri-ciri nilai Islam, akan merangsang peserta didik untuk menghubungkan konsep matematika yang dipelajari dengan kejadian, masalah kehidupan, terutama yang berkaitan dengan pelaksanaan ibadah (Setiawati et al., 2018). Selain itu, integrasi pembelajaran dan al-Qur'an menjadikan materi pembelajaran mudah dipahami, sekaligus memunculkan nilainilai yang baik dan akhlak mulia membentuk peserta didik yang mempunyai kemampuan iman dan takwa serta ilmu pengetahuan dan teknologi yang sesuai dengan tujuan pendidikan nasional (Harahap, 2018).

Penelitian ini sejalan dengan konsep integrasi yang dikemukakan Mutijah (2018). Metode yang digunakan dalam integrasi matematika dengan Al-Qur'an dan budaya lokal adalah menjadikan al-Qur'an dan budaya lokal sebagai referensi ilmu matematika.

\section{KESIMPULAN DAN SARAN}

Berdasarkan tujuan penelitian dan hasil penelitian yang didapat maka dapat disimpulkan bahwa: Lembar Kerja Peserta Didik (LKPD) 
matematika berwawasan al-Qur'an dan budaya Minangkabau untuk peserta didik kelas $\mathrm{X}$ materi sistem persamaan linier tiga variabel dinilai valid dan praktis.

Penelitian ini masih sampai tahap develop, maka diharapkan untuk selanjutnya LKPD matematika berwawasan al-Qur'an dan budaya Minangkabau ini dapat diujicobakan dalam skala luas atau dilakukan tahap disseminate melalui internet. Penelitian selanjutnya yang terkait integrasi nilainilai Islam dalam pembelajaran matematika tidak hanya sebatas penggunaan al-Qur'an tetapi menggunakan nilai-nilai agama yang menyeluruh meliputi, hadis, sejarah/ sirah dan lainlainnya. Pendidik dapat menggunakan aspek budaya dalam pembelajaran matematika tidak sebatas sebagai konteks, tetapi menciptakan kegiatan belajar matematika melalui budaya atau menggali konsep matematika melalui budaya.

\section{DAFTAR PUSTAKA}

Abiam, P. O., Abonyi, O. S., Ugama, J. O., \& Okafor, G. (2016). Effects of Ethnomathematics-based Instructional Approach on Primary School Pupils 'Achievement in Geometry. Journal of Scientific Research\&Reports, 9(2), 1-15. https://doi.org/10.9734/JSRR/2016 /19079

Al-Faqih, K. M. S. (2017). A Mathematical Phenomenon in the Quran of Earth-Shattering Proportions: A Quranic Theory Based On Gematria Determining Quran Primary Statistics (Words, Verses, Chapters) and Revealing Its Fascinating Connection with the Golden Ratio. Journal of Arts and Humanities, 6(6), 52-73. https://doi.org/10.18533/journal.v6 i6.1192

D'Entremont, Y. (2015). Linking mathematics, culture and community. Procedia - Social and Behavioral Sciences, 174(1999), 2818-2824.

https://doi.org/10.1016/j.sbspro.20 15.01.973

Fitriza, R., \& Gunawan, I. (2018). Tabuik dalam Pembelajaran Bangun Ruang dengan Pendekatan Pendidikan Matematika Realistik ( PMR ). 2(1), 13-22.

Hamdi, S., \& Ermawati, S. (2018). Implementasi Penilaian Autentik: Model Perangkat Pembelajaran dan Penilaian Matematika Dengan Pendekatan CTL Berbasis Budaya Islam. Educatio, 13(2), 110-121. https://doi.org/10.29408/edc.v13i2. 1054

Harahap, A. (2018). Integrasi Alquran Dan Materi Pembelajaran Kurikulum Sains Pada Tingkat Sekolah Di Indonesia: Langkah Menuju Kurikulum Sains Berbasis Alquran. Jurnal Penelitian Medan Agama, 9(1), 21-46.

Hussain, L. K. ., \& Ramli, A. F. (2017). Contributions of Islamic civilization to the mathematics development. Wawasan: Jurnal Ilmiah Agama Dan Sosial Budaya, 2(2), 199-208.

Idris, K. (2019). Literasi Statistik Berbasis Konteks Budaya dan Keislaman: Perspektif Dosen dan Mahasiswa PTKI. Prosiding Seminar Nasional IItegrasi Matematika Dan Nilai Islami, 3(1), 357-362.

Istiqlal, M., \& Jumadi, J. (2017). Strengthening Islamic character through Mathematics learning. MUDARRISA: Jurnal Kajian Pendidikan Islam, 9(2), 188-207. https://doi.org/10.18326/mdr.v9i2.188 $-207$ 
DOI: https://doi.org/10.24127/ajpm.v9i4.3212

Junaidi, Susilawati, N., Fernandes, R., Sylvia, I., \& Putra, E. V. (2020). Integration of Al-Quran Education and Minangkabau Culture on Subjects in Formal Schooling. Advances in Social Science, Education and Humanities Research, 405(Iclles 2019), 139144. https://doi.org/10.2991/ assehr.k.200217.029

Muslimahayati. (2020). Pengembangan Soal kemampuan berfikir Kritis Berbasis Kearifan Lokal Sumatera Selatan pada Materi Trogonometri. AKSIOMA: Jurnal Program Studi Pendidikan Matematika, 9(1), 1220.

Mutijah. (2018). Model Integrasi Matematika dengan Nilai-nilai Islam dan Kearifan Lokal Budaya dalam Pembelajaran Matematika. Jurnal Pendidikan Matematika, 1(2), 51-75.

Nu'man, M. (2016). Pembelajaran Matematika Dalam Perspektif Alquran. JPM : Jurnal Pendidikan Matematika, 2(1), 39-49. https://doi.org/10.33474/jpm.v2i1. 205

Prastowo, A. (2014). Pengembangan bahan ajar tematik tinjauan teoritis dan praktis. Prenadamedia group.

Ricardo, R. (2020). Pembelajaran Matematika Melalui Konteks Islam Nusantara: Sebuah Kajian Etnomatematika di Nusantara. Jurnal Pendidikan Matematika, 3(1), 86-98.

Riduwan. (2012). Belajar mudah penelitian untuk guru-karyawan dan peneliti pemula (9th ed.). Alfabeta.

Rizka, S., \& Mastur, Z. (2014). Model Project Based Learning Bermuatan Etnomatematika untuk
Meningkatkan Kemampuan

Koneksi Matematika. Unnes Journal of Mathematics Education Research, 3(2), 72-78.

Rosa, M., \& Orey, D. C. (2011). Ethnomathematics: the cultural aspects of mathematics Etnomatemática : os aspectos culturais da matemática. Revista Latinoamericana Etnomatemaatica, 4(2), 32-54.

Sarmalena, G., \& Susanti, R. (2017). Pedoman Pengintegrasian Pendidikan Al Qur'an dan Budaya Alam Minangkabau pada Mata Pelajaran Matematika Sekolah Menengah Atas (SMA) (p. 161). Dinas Pendidikan Provinsi Sumatera Barat.

Setiawan, A., \& Thahir, M. (2016). Pembelajaran Matematika Dasar Berintegrasi Keislaman untuk Meningkatkan Sikap Religiusitas Siswa. The Dynamics of Malay Islamic World in Responding to Contemporary Global Issues, 155.

Setiawati, R., Netriwati, \& Nasution, P. S. (2018). Desain Model Pembelajaran Gerlach dan Ely yang Berciri Nilai-nilai KeIslaman untuk Meningkatkan Kemampuan Komunikasi Matematis. Aksioma: Jurnal Program Studi Pendidikan Matematika, 7(3), 371-379.

Sugilar, H., Rachmawati, T. K., \& Nuraida, I. (2019). Integrasi interkoneksi matematika agama dan budaya. Jurnal Analisa, 5(2), 189-198.

https://doi.org/10.15575/ja.v5i2.6717

Thiagarajan, S., Semmel, D., \& Semmel, M. (1974). Instructional development for training teachers of exceptional children: A sourcebook. Indiana University. 